\title{
Tsada-Mobiminder: A Location Based Alarm Mobile Reminder
}

\author{
http://dx.doi.org/10.3991/ijes.v3i4.5226 \\ Marylene Saldon Eder \\ Mindanao University of Science and Technology, Philippines
}

\begin{abstract}
Existing location based alarm applications has inability to give information to user's particular direction to a specified place of destination and doesn't display a particular scenic spot from its current location going to the destination. With this problem, a location based alarm mobile reminder was developed. The application is implemented on Android based smart phones to provide services like providing routing information, helping find nearby hotels, restaurants and scenic spots and offer many advantages to the mobile users to retrieve the information about their current location and process that data to get more useful information near to their location. It reminds the user about the location when the user enters some predefined location. All the user needs to have is the mobile phone with android platform with version 4.0 and above, and then the user can select the destination and find the destination on the application. The main objective of the project is to develop a location based application that provides tourists with real time information for scenic spots and provides alarm to a specified place of destination. This mobile application service will act as assistance for the frequent travelers to visit new places around the City.
\end{abstract}

Index Terms-Location Based Alarm, Mobile Application, Mobile Reminder, Tourist's Spots.

\section{INTRODUCTION}

A Location Based Service (LBS) is an information and entertainment service, accessible with mobile devices through the mobile network and utilizing the ability to make use of geographical position of the mobile device. This service can be used in a variety of contexts, such as health, work, and personal life. It include services to identify the location of a person or object, such as discovering the nearest banking cash machine or historical places and includes parcel tracking and vehicle tracking services. It has two major actions, which are obtained by the location of a user and utilizing this information to provide a service (Kushwaha, et al, 2011).

Location-based services refer to a set of applications that exploit the knowledge of the geographical position of a mobile device in order to provide services based on that information. It provides the mobile clients personalized services according to their current location (Vanjire et al, 2014).

According to Tzu-How-Chu et al (2011), GPS techniques are applied to provide guiding information and manage tourism destinations more effectively. GPS techniques are integrated using mobile devices to provide location-based guiding information as needed. The increasing demand for information at popular tourism desti- nations has driven tourism specialists to focus on finding better guiding solutions. Guiding information services have become more important at popular tourism destinations.

Location based alarm using GPS is an attempt to add an alarm facility for mobiles, based on the location of the device and to find the nearest places from the current location of the mobile device. The location based alarm gives the user an alert when he reaches his desired destination. Location based alarm is a GPS based alarm, If the alarm is set, it makes a sound and notification. It is detected within the user's defined range from the destination (Vasuki et al, 2014).

There are problems of existing location based alarm systems such that they do not inform the user in a particular direction or to a specified place of position. Although location based applications have been widely prototyped, there are few results regarding their impact on people, how they are used, how they change people's behavior, and what features influence usefulness the most (Priyanka Shah et al, 2012). There are also location based alarm that are for alarming purposes only but not in informative way like providing information through reminder and alarm. Existing location based alarm is designed only for passengers and travelers but does not advertise or promote the City's' tourist spots of any particular place through providing a reminder which is important for the Department of Tourism in contributing to the growth of the City's tourism.

The researchers conducted an interview with the Department of Tourism. They said that tourism is one of the most important factors for a city to be productive and progressive. This gave the researchers the idea to come up with an application which helps to promote different spots in the City through a reminder.

To address the existing problems, the researchers have developed a mobile application that allows the user to set a desired destination and be reminded upon the arrival on that certain location. This application also provides information about scenic and tourist spots around Cagayan de Oro City with real time guiding information.

\section{METHODOLOGY}

\section{A. Designing the Mobile Application for Location Based Alarm}

System architecture shows the overall architecture of the application. When the mobile device enters the range of specified radius for which the user has set destination and it trigger's the alarm notification and it gets users current location (latitude and longitude) by requesting the 
GPS (Global Positioning System). If the mobile device is moving from the user's current location going to the set destination. It saves the mobile device latitude and longitude retrieve from GPS and stored in the device to get the updated user location and it provides an alarm with a reminder. The reminder is given to the user whenever user enters the particular range of the specified location. Depending on the range specified, user is reminded of the scenic spots the user has passed by at or near the given location.

System architecture shows the overall architecture of the application. When the mobile device enters the range of specified radius for which the user has set destination and it trigger's the alarm notification and it gets users current location (latitude and longitude) by requesting the GPS (Global Positioning System). If the mobile device is moving from the user's current location going to the set destination. It saves the mobile device latitude and longitude retrieve from GPS and stored in the device to get the updated user location and it provides an alarm with a reminder. The reminder is given to the user whenever user enters the particular range of the specified location. Depending on the range specified, user is reminded of the scenic spots the user has passed by at or near the given location.

\section{B. Context Diagram}

Figure 2 shows how the system receives and sends data to the external entities involved. It also illustrates the general flow of the system. The tourist is the user of the system. The user can set specific destination that alarms when the user is within the set range of alarm notification

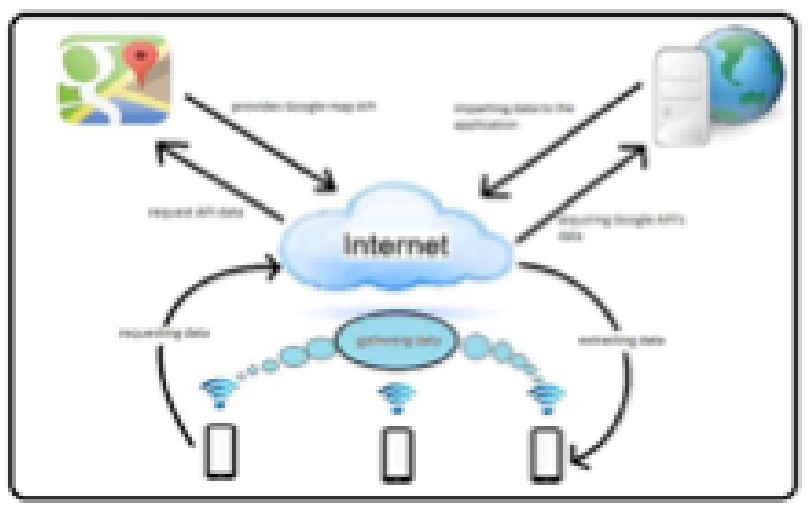

Figure 1. System Architecture of the Application

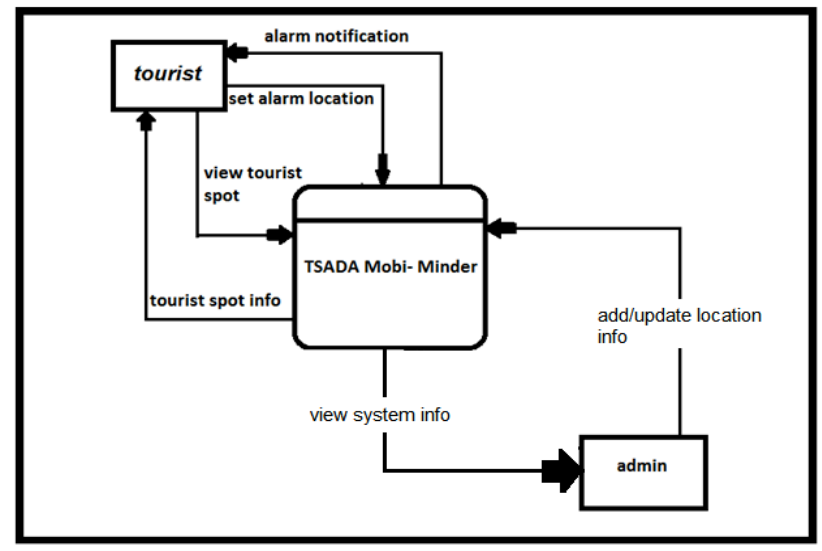

Figure 2. Context Diagram of the Application

\section{Data Flow Diagram}

and can also view the reminder that notifies and provides data on the places that they had passed by. On the other side, the admin is the one who add, update and view the local information, spot description and the spot information of the location to the system.

Figure 3 shows how the user and the admin access the mobile and web application. The user should have internet connection to access the mobile application. The mobile application uses Google API / web server to transmit data requested by the user.IT can set specific destination / location to request data from Google map Geo location API to get the latitude and longitude of the searched place. It will also get data of latitude and longitude from user's current location to destination to create a route path to the map. The users can search different type of places by requesting to Google Places API by showing all the places as a marker in the map so that the user knows what are the places that the user may passed by .On the other hand, the admin use the web application to add data such as spots, hotels, and restaurants around Cagayan de Oro City. The Admin can update and delete of the searched local location information that are existing here in Cagayan de Oro City. The data added by the admin became the markers on the mobile application.

Figure 4 shows how to get the API Key from Google Developers Console. This key is used to authenticate your application for accounting purposes. Android key if your application runs on Android devices.

Figure 5 shows that the developers used Google Maps Android v2 for the version of map used for the application. It is used to activate or enable the API's that the application used.

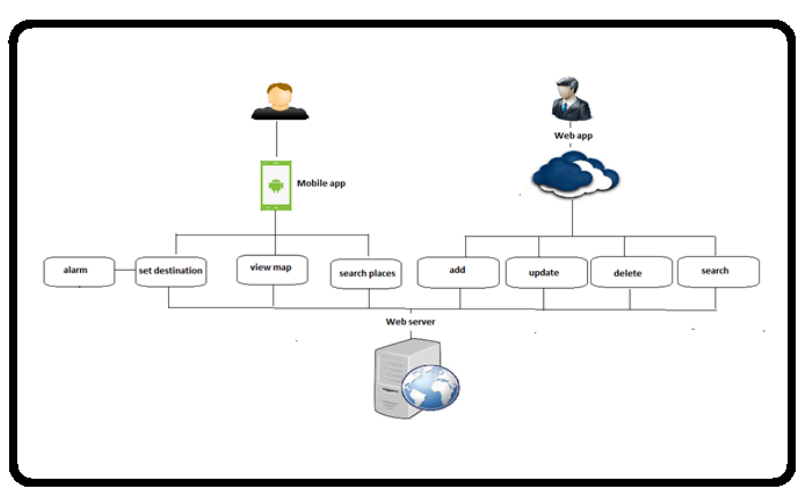

Figure 3. Data Flow Diagram of the Application

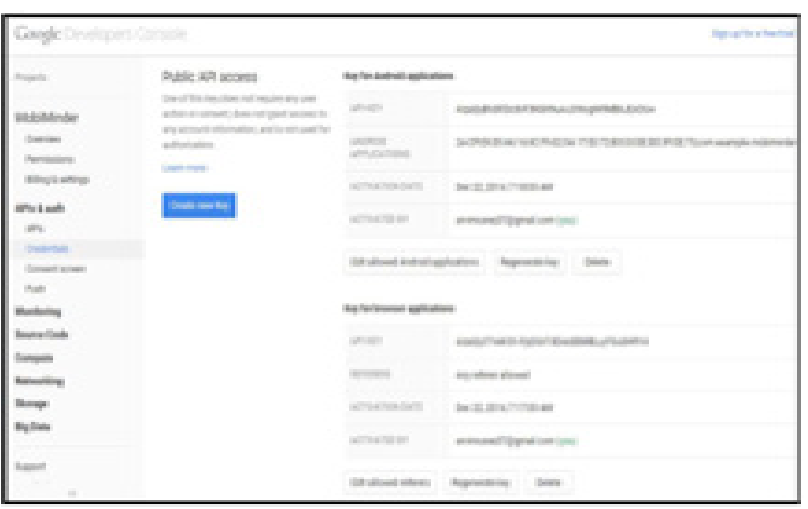

Figure 4. Screen shot on how to get API key from Google Developers Console 


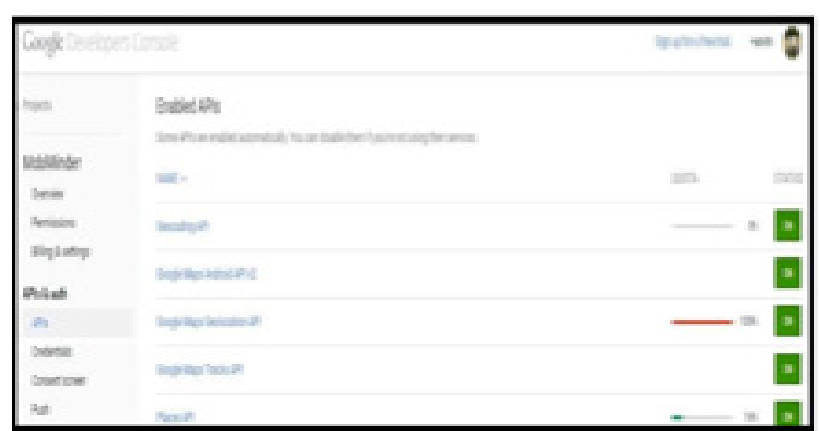

Figure 5. Screen shot for enabling the API's that is needed for the application

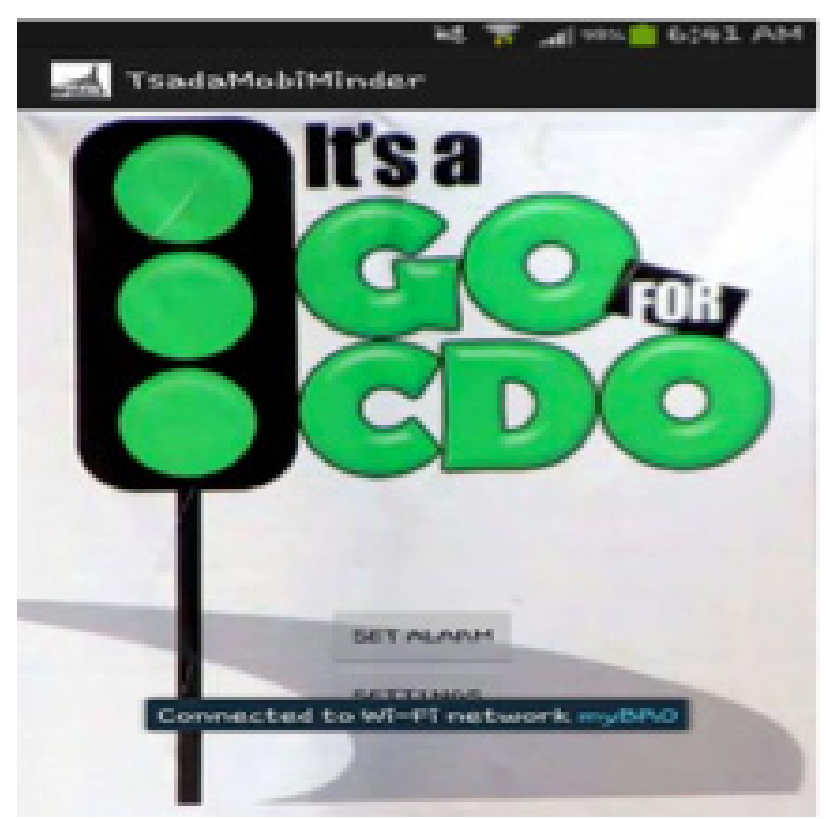

Figure 6. Screen shot of the Home Page of the mobile application

Figure 6 shows the "home page" of the application. This is the first page the user sees. This page has (2) two buttons - Set Alarm and Users Guide. The Set Alarm button provides the map where the user can set his desired destination, look for the nearest places and view guiding information from the application. The User's Guide button provides the instructions on how the user uses the application together with the legends of the map.

\section{RESULTS AND DISCUSSION}

\section{A. Evaluation of the Application}

The researchers used the standard questionnaire for evaluating a system application.

Table I presents the results for system usability scale. Based on the data above, majority of the respondents strongly agree that the application is easy and simple to use.

Table II shows the result of the functionality test on the survey. All 20 respondents agreed to all the questions on the survey questionnaire. All respondents agreed that the applications functionality was achieved.
TABLE I.

RESUlT OF THE SYSTEM USABILITY SCALE

\begin{tabular}{|c|c|c|c|}
\hline QUESTIONS & $\begin{array}{c}\text { STRONGLY } \\
\text { AGREE }\end{array}$ & MODERATE & $\begin{array}{c}\text { STRONGLY } \\
\text { AGREE }\end{array}$ \\
\hline 1 & $\mathbf{7 0 \%}$ & $\mathbf{3 0 \%}$ & $\mathbf{0 \%}$ \\
\hline 2 & $\mathbf{4 0 \%}$ & $\mathbf{4 5 \%}$ & $\mathbf{1 5 \%}$ \\
\hline 3 & $\mathbf{6 5 \%}$ & $\mathbf{2 5 \%}$ & $\mathbf{1 0 \%}$ \\
\hline 4 & $\mathbf{2 0 \%}$ & $\mathbf{4 0 \%}$ & $\mathbf{4 0 \%}$ \\
\hline $\mathbf{5}$ & $\mathbf{6 5 \%}$ & $\mathbf{3 5 \%}$ & $\mathbf{0 \%}$ \\
\hline $\mathbf{6}$ & $\mathbf{2 5 \%}$ & $\mathbf{4 0 \%}$ & $\mathbf{3 5 \%}$ \\
\hline 7 & $\mathbf{7 5 \%}$ & $\mathbf{2 5 \%}$ & $\mathbf{0 \%}$ \\
\hline $\mathbf{8}$ & $\mathbf{3 5 \%}$ & $\mathbf{2 5 \%}$ & $\mathbf{4 0 \%}$ \\
\hline $\mathbf{9}$ & $\mathbf{7 0 \%}$ & $\mathbf{2 0 \%}$ & $\mathbf{1 0 \%}$ \\
\hline 10 & $\mathbf{3 5 \%}$ & $\mathbf{3 0 \%}$ & $\mathbf{3 5 \%}$ \\
\hline Average & $\mathbf{5 0 \%}$ & $\mathbf{3 1 . 5 \%}$ & $\mathbf{1 9 . 5} \%$ \\
\hline
\end{tabular}

TABLE II.

THE RESULT OF SYSTEM FUNCTIONALITY SCALE

\begin{tabular}{|l|l|l|}
\hline Functionality Test & YES & NO \\
\hline $\begin{array}{l}\text { Does the application } \\
\text { provide real-time guiding } \\
\text { information? }\end{array}$ & $100 \%$ & $0 \%$ \\
\hline $\begin{array}{l}\text { Does the application } \\
\text { provide path/route when } \\
\text { setting desired destination? }\end{array}$ & $100 \%$ & $0 \%$ \\
\hline $\begin{array}{l}\text { Does the application } \\
\text { provide notification when } \\
\text { arriving to a specific } \\
\text { desired destination? }\end{array}$ & $100 \%$ & $0 \%$ \\
\hline $\begin{array}{l}\text { Does the application help } \\
\text { the user in searching } \\
\text { specific location? }\end{array}$ & $100 \%$ & $0 \%$ \\
\hline $\begin{array}{l}\text { Is the application easy to } \\
\text { access by the user? }\end{array}$ & $100 \%$ & $0 \%$ \\
\hline
\end{tabular}

\section{CONCLUSIONS AND RECOMMENDATIONS}

\section{A. Conclusion}

Android provides a very nice platform for developing LBS applications. Location Based Services are those services which provide information which is accessible with mobile devices through the mobile network.

The main goal of this study is to develop a mobile application that allows the user to set desired destination and be reminded upon the arrival on that certain location and provides information about scenic and tourist spots the user had passed through around Cagayan de Oro City with real time guiding information. After everything is done, it is then concluded that with the development of TsadaMobiMinder application, tourists are now guided using their android mobile phones as a tool. Users can easily monitor their current location since some of the tourists are not familiar with all the places around Cagayan de Oro. So by installing and using this application, users are now aided and guided through all the places around the City. 


\section{B. Recommendations}

This chapter contains recommendations with regards to the study of Tsada- MobiMinder in an Android Application. 1. To fully utilize the application without hindrances, resolve the accuracy issue must be resolved. The systems are not always updated, so we the researchers do not know when a road has been closed or when a new road has been opened. The updating comes across as a major hindrance.

2. The problem of internet connectivity must be resolved. GPS does not provide accurate information about the users' location when the internet connection is slow.

3. The exact calculation must be given in providing the complete detail of a certain location when tapping the Information.

4. This application must save all the data of the map after the request, so that if the user will lose or turnoff his Internet connection the last transaction between this application with the Google Maps will be available and ready to use by the users for his destination.

\section{REFERENCES}

[1] Al Jhawari et al. (2014). Location based Alarm using Mobile Device, International Journal of Computer Applications, Majan College International Conference.

[2] David Ronnqvist. (2011). There: Location- Based Reminders in a Mobile Phone, Master of Science Thesis Stockholm, Sweden.

[3] Kushwaha et al. (2011). Location Based Services using Android Mobile Operating System, International Journal of Advances in Engineering \& Technology, Vol. 1,Issue 1,pp.14-20.

[4] Manav Sighal et al. (2012). Implementation of Location based Services in Android using GPS and Web Services, IJCTS International Journal of Computer Sciences Issues, Vol.9, Issue 1, No 2. Retrieved September 2014.

[5] Rani et al. (2012). Location Based Services in Android, International Journal of Advances in Engineering \& Technology.

[6] Sawsan Alshattnawi. (2013). Building Mobile Tourist Guide Applications using Different Development Mobile Platforms, In- ternational Journal of Advanced Science and Technology Vol. 54, 13-22. Retrieved February 2015.

[7] Wijesuriya et al. (2013). Interactive Mobile Based Tour Guide, SAITM Research Symposium on Engineering Advancements.

[8] Garg et al. (2013). GEO ALERT- A Location Based Alarm System Using GPS in Android, International Journal of Multidisciplinary in Cryptology and Information Security, Volume 2, No.3.

[9] Shah et al. (2012). Location Based Reminder Using GPS For Mobile (Android), ARPN Journal of Science and Technology, VOL. 2, NO. 4

[10] Tzu-How Chu et al. (2011). Developing a Tour Guiding Information System for Tourism Service using Mobile GIS and GPS Techniques, Advances in Information Sciences and Service Sciences, Volume3, Number6.

[11] Angadi et al. (2013). Friendly MobiMinder- Reminder Based On User's Location Using GPS, International Journal of Emerging Technology and Advanced Engineering, Certified Journal, Volume 3, Issue 1

[12] Uddin et al. (2013). GPS-based Location Tracking System via Android Device, International Journal of Research in Computer Engineering and Electronics. Page \# 1 ISSN 2319-376X VOL :2 ISSUE : 5 .

[13] Vasuki et al. (2014). Location Based Alarm System Depending on Logitude and Lattitude, International Journal of Computer Science and Information Technologies, Vol. 5 (1).

[14] Vanjire at al. (2014). Location Based Services on Smart Phone through the Android Application, International Journal of Advanced Research in Computer and Communication Engineering, Vol. 3, Issue 1

[15] Pawar et al. (2009). Time and Location Based Reminder System, Nauonal level paper presentation Excelsior '09 at SeOE,Pune.

\section{AUTHOR}

Marylene Saldon Eder is with Mindanao University of Science and Technology, Philippines.

Submitted 09 November 2015. Published as resubmitted by the author 30 November 2015 